\title{
Deterrence versus Intrinsic Motivation: \\ Experimental Evidence on the Determinants of \\ Corruptibility
}

\author{
by \\ Günther G. Schulze*® \\ University of Konstanz \\ and \\ Björn Frank \\ University of Hohenheim
}

\begin{abstract}
This paper reports on an experiment of corruption that was conducted in two treatments: one with the possibility of detection and one without. It turns out that monitoring motivation for honesty. Thus the net effect on overall corruption is a priori undetermined. We show that the salary level has an influence on corruption through
\end{abstract}

Interesting policy conclusions emerge.

JEL classification

Keywords

Corresponding author. University of Konstanz, PO Box D 141, 78457 Konstanz, Germany, email Guenther.Schulze@uni-konstanz.de, Fax ++49-7531-884091. 


\section{Introduction}

Corruption is one of the most pressing problems of today's governments. It devours resources, leads to inefficient bureaucracies and misallocation of resources and reduces growth and development. Although a number of empirical studies have inquired into the macroeconomic consequences of corruption (see Tanzi 1998 for an overview), the microeconomic determinants of individual corruptibility remain largely in the realm of educated guesses or speculation. Systematic empirical evidence on the microeconomic determinants of corruption is hindered by a notorious lack of data. Clandestine by its very nature, corruption is hard to measure and unlike tax evasion there is no institution that systematically monitors individual corruption activity on a regular basis.

Systematical evidence on the determinants of corruption, however, is highly desirable as it would allow to assess the different proposals for fighting corruption. For example, is the observed negative correlation between public officials' wages and the degree of corruption (van Rijkeghem and Weder 1997) due to increased loyalty towards the state if people are paid 'fairly' or due to increased opportunity costs when caught cheating as people would just have more to lose? If the latter was the case, stricter law enforcement would likewise increase opportunity costs, but it might turn out detrimental if the loyalty effect is dominant as stricter law enforcement may erode the intrinsic motivation.

Recent research has shown that the impact of monitoring and pay on agents' behavior is far from trivial. The traditional view posits that law enforcement deters from criminal activity. Yet, recently pecuniary incentives have been shown to destroy agents' intrinsic motivation to follow their principals' interests (e.g., Frey and Oberholzer-Gee, 1997). Contrastingly, increased pay might evoke loyalty by the agent - even if the cessation of 
pay is not an available sanction - because agents are still motivated by reciprocity (e.g., Fehr, Kirchsteiger and Riedel, 1993).

Our experiment on corruption is particularly suited to address these questions because it is the first experiment to generate systematical empirical evidence on corruption and thus overcomes the persistent lack of data. It was conducted in two treatments, one in which subjects were not exposed to monitoring and the risk of being caught, and another in which they faced the risk of detection with a certain probability. The comparison of these two treatments produces insights into the role of monitoring for corruption through deterrence and its effect on intrinsic motivation. Furthermore, it provides results on other determinants of corruptibility such as gender, wage level, and field of study.

Our approach complements, but differs considerably in focus from the existing experimental literature on the role of intrinsic motivation, fairness and reciprocity. First and foremost, corruption is a very different principal agent situation than those analyzed by the literature on reciprocity ${ }^{1}$. Corruption has very different legal and moral implications than, say, shirking in the workplace. Moreover, unlike existing experiments on reciprocity which involve only two players, corruption involves essentially three parties: the briber, the bribee, and those harmed by the corruption. ${ }^{2}$ On these grounds we should expect the interaction to follow different patterns than in the reciprocity literature. Also, the literature on crowding out of intrinsic motivation (e.g., Frey, 1997) has been concerned with how pecuniary rewards destroy intrinsic motivation whereas we analyze whether monitoring of and sanctions for illegal activities may crowd out the motivation to be honest. In addition, this paper explicitly introduces risk (of detection), whereas the crowding out literature up to now has assumed certainty.

\footnotetext{
${ }^{1}$ See Fehr and Gächter (1998) for an overview.

${ }^{2}$ In case of public procurement corruption this would be the firm which would otherwise have won the
} 
The paper is organized as follows: The hypotheses which we test by this approach are set out in the next section. Section 3 describes the experimental design, and section 4 presents the results. Section 5 discusses some tentative policy implications and concludes.

\section{Hypotheses}

Two most frequently suggested approaches to fight corruption, in the literature and in public debates, have been to increase in auditing and penalty and to raise government officials' pay $^{3}$. However, it is still an open question how effective these measures are and how they translate into higher compliance, let alone how they interact. This is what we will analyze, starting with a closer look at the suggested measures in turn.

\subsection{Increase of auditing: deterrence vs. crowding out of intrinsic motivation}

Other things being equal, increasing the probability of detection reduces the expected utility derived from any crime. Following Becker (1968) in the assumption that criminals maximize utility, a prediction of their reactions follows. This argument seems particularly reasonable for the decision whether to accept bribes or not, as this decision is made more repeatedly, less spontaneously and in a less fiery mood than is the case of many other crimes. This gives us

Hypothesis 1: Increased monitoring reduces corruption.

Empirical support already exists for classical types of crime (e.g., Levitt, 1997), but not

bidding and the public which incurs greater costs.

3 Kaufmann (1997) asked 150 managers and government officials from countries most plagued by corruption to rate the effectiveness of various anti-corruption measures. Together with "set example by leadership", a raise in public sector salaries and stiff penalties received a high rating most often. To set an example by leadership is outside the scope of our experiment; however, economists should have something to say about this, too (cf. Tirole 1996). 
for corruption: Goel and Rich (1989) find that the real police expenditure per government employee does not have a significant impact on the proportion of all government employees who are convicted of bribery in the respective area. However, our approach differs from this study in that no such heroic proxy variables for corruption, probability of detection and severity of punishment are used; our test is straightforward: Whereas in one treatment corrupt subjects can be detected and punished ('risk treatment'), any level of corruption goes undetected in the other ('nonrisk treatment'). According to hypothesis 1, we should observe a lower degree of corruptibility in the risk treatment than in the non-risk treatment.

Alternatively, it has recently been suggested that economic incentives might crowd out intrinsic motivation. For example, Frey and Oberholzer-Gee (1997) found that people's inclination to accept a nuclear waste repository decreased when they were offered a financial compensation. Here "civic duty" (p.748) is crowded out by positive incentives ${ }^{4}$. Gneezy and Rustichini (1998) found in an IQ test that those subjects who get no reward at all perform better than those with a small reward (but worse than subjects with a sufficiently high reward).

Applying this line of reasoning to our case, we would expect the introduction of monitoring to crowd out the intrinsic motivation to reject bribes. Monitoring reveals that the principal no longer trusts the agent. Then, at least for halfhearted monitoring, its negative effects might outweigh any positive effects. In other words:

Hypothesis 2: The introduction of monitoring reduces honesty.

Note that, unlike Frey and Oberholzer-Gee or Gneezy and Rustichini (1998), the factor destroying the intrinsic motivation is not a fixed payment but the possibility of being

\footnotetext{
${ }^{4}$ This is not counterintuitive as one might think at first: "If a person derives intrinsic benefits simply by behaving in an altruistic manner or by living up to her civic duty, paying her for this service reduces her option of indulging in altruistic feelings." Frey and Oberholzer-Gee (1997), p.746-7. See also Frey (1997).
} 


\section{o}

monitored, i.e. a stochastic event. So far only anecdotal evidence ${ }^{5}$ suggests that this may also cause crowding out. Maybe it is the most interesting aspect of our experiment that it generates systematic evidence on this point.

Hypotheses 1 and 2 do not preclude each other. We only observe the net effect of these opposite forces, which should however have different weights on the two tails of the distribution of corruption levels in the experiment. If the share of honest people is reduced through the introduction of monitoring, the crowding out effect must have outweighed the deterrence effect. The deterrence effect might however keep people from taking even higher bribes. On the other hand, if probability mass on the high end of the corruption is reduced, the deterrence effect dominates the crowding out effect for this part. Someone with the maximum degree of corruptibility can safely be presumed to be devoid of intrinsic motivation, thus his reaction to monitoring can be ascribed to deterrence alone.

\subsection{Increased salary}

There have been repeated suggestions that low wages in the public sector - especially in developing countries - are a major cause of corruption, and that increasing these wages would restrain corruption (e.g., Besley and McLaren 1993, p.120, Klitgaard 1996, p.43). Goel and Rich (1989), in their cross-section study of the determinants of corruption on the national (US) level, do indeed find a correlation between public sector pay and a proxy for corruptibility. However, it is not possible to infer from their data to what extent the two possible underlying mechanisms contribute to this correlation: First, higher payment increases the opportunity costs of corruption, and second, it increases

\footnotetext{
${ }^{5}$ Frey (1993, p.1529) mentiones the Swiss bureaucracy's monitoring of the professors' teaching at the universities. As a reaction, those who previously overfulfilled their duties (i.e., taught more than eight hours per week) no longer work more than necessary: "work ethic" is crowded out.
} 
loyalty. ${ }^{6}$

Let us consider first whether payment could matter even if the agents do not run the risk of being detected and fired. A first indication that this may be true is given by the gift exchange game. Experimental investigations of the gift exchange game (Fehr, Kirchsteiger and Riedel, 1993; Falk, Gächter and Kovács, forthcoming) show that participants who take the role of workers choose a higher effort level if they are better paid. In the gift exchange game it is costly to choose a higher effort, and low effort levels cannot be punished as the employer moves first by choosing a level of pay. Thus, high wages successfully appeal to a sense of reciprocity in this game.

However, it is not obvious that these results carry over to corruption, simply by interpreting honesty as an effort. The structure of the problem is different. In case of the gift exchange game, or the shirking problem in general, the principal offers the wage to the agent and is directly affected by his work effort which he returns in exchange for the payment. In contrast, the person who offers the wage and the one who benefits from the worker's effort (i.e., honesty) are typically not identical in the case of corruption. To give an example, on one occasion one of us has been offered a bribe by a student, which has been refused. Who has benefited from this refusal? Mainly the other (honest) students, whose diploma have been saved from being devalued ${ }^{7}$. However, in Germany, we are not paid by the students, i.e. the group that has benefited from our 'work effort' (of rejecting). Likewise, in our experiment, the subjects are paid by the experimenters, not by those who benefit if the agents are honest. In this institutional setting, it is not

\footnotetext{
${ }^{6}$ Another reason why higher wages might lead to less corruption is that accepting bribes might then no longer be absolutely necessary for living (Spinellis 1996, p.25), but obviously this does not apply to the study by Goel and Rich (1989).

${ }^{7}$ They would have been devalued as, after a successful act of corruption, all but one student would have a lower score relative to the average score, ceteris paribus. A more drastic case is the construction of the Turkwel Gorge dam in Kenya, for which there was no international competitive bidding. Had it not been constructed in a technically inferior way, at a price (270 millions \$) including bribes, it would produce energy at less than half of the actual current costs (Moody-Stuart, 1997, p.22). Had the decision been made by a loyal official, it would not primarily be his employer, the government, who would have been
} 
clear whether reciprocity still plays a role. ${ }^{8}$ If it does, this leads to

Hypothesis 3: Even in the absence of monitoring, the level of pay matters for the corruptibility of agents.

According to this hypothesis, we should expect a fixed payment to already reduce corruption in the first treatment of our experiment.

The second and more straightforward reason why a higher salary should result in lower corruption is that it implies higher opportunity costs of corruption. If corrupt officials run the risk of being caught and fired, and if thereafter they earn less than they would in the public sector, an incentive for refusing to take bribes is constituted. The classical reference is Becker and Stigler (1974), who made this point with respect to the compensation of law enforcers. ${ }^{9}$ This leads to our

Hypothesis 4: Better paid agents tend to reduce their corruptibility more upon the introduction of monitoring (i.e., on the risk of being detected and losing income).

Note that this effect is only caused by the risk of losing income; it will only materialize in addition to any loyalty effect of higher income in the second treatment. Thus, if the effect of a fixed salary is larger in our second treatment than in the first one, this is due to the opportunity costs of corruption.

\subsection{Corruption and Gender}

It has been argued frequently that women behave systematically different from men in

better off, but the citizens.

8 Charness (1997) finds that in his experimental variant of the gift exchange game, the effect of high wages on effort level is lower (though not absent) if the payment decision is not made by the one who benefits from the effort.

9 This argument bears resemblance to the efficiency wage hypothesis which was proposed only later (Shapiro and Stiglitz 1984). 
certain economic situations and social interactions. Possibly their inclination to accept bribes is also different, which would be interesting to find out. Although it is true that the sex of an agent is not a variable under the control of the state, the gender composition of the civil service certainly is. Peru's president Alberto Fujimori has decided to hire only women for Lima's traffic police, the reason being that they have earned a reputation as incorruptible among drivers. ${ }^{10}$

Not only do we test this hypothesis; if we find support for the "Fujimori-hypothesis", we can also discriminate two possible reasons why women are less corrupt. The first is that women's lower inclination to accept bribes simply reflects their greater loyalty and cooperation, for which the literature provides mixed evidence. ${ }^{11}$ Following folk wisdom we formulate the following hypothesis:

Hypothesis 5: Women are generally less corruptible than men, also in riskless situations.

The second possible reason for a lower corruptibility of women is that they are on average more risk averse than men (Jianakoplos and Bernasek, 1997; Brinig, 1997; Donkers, Melenberg and van Soest, 1998). This gives us

Hypothesis 6: The effect of auditing on corruption is greater for women than for men.

Of course, such an effect would only show up in the risk treatment whereas a greater cooperation of women would affect both treatments. Again the comparison of the two treatments allows us to identify the forces at work.

\footnotetext{
${ }^{10}$ Cf Bild, 27.7.98, p.2 or Star Net / The Arizona Daily Star Online, 24.8.98. Even if one does not follow Fujimori's policy implications, it is clear that one should control for gender in the empirical analysis, just like we will have to control for the subjects' education, as it has been shown elsewhere (e.g., R. Frank et al., 1993; Frank and Schulze, forthcoming) that economics mayors tend to be less cooperative than their non-economic counterparts. However, given that economic expertise is deplorably underrepresented in many governments, we do not suggest any policy implications.

11 Bolton and Katok (1995) find no gender differences with respect to altruism in the dictator game, but
} 


\subsection{Synopsis}

Corruption in real life is characterized by the prevalence of the risk of detection and punishment, though to various degrees. In these risky situations, different effects are at work: people are deterred from being corrupt while their intrinsic motivation for being honest is simultaneously crowded out; a higher salary could possibly increase loyalty towards the principal and at the same time increases opportunity costs of corruption; women may either genuinely be more cooperative or as a result of higher risk aversion.

In order to single out the various determinants of corruption and to assess their relative strengths, we need to compare a risky situation with a non-risk situation. The differential effects at work in these two situations are shown in Table 1, grouped in accordance with sections 2.1.-2.3. above.

Table 1 about here

In other words, we need to artificially create a riskless situation as a benchmark, against which we can compare the more realistic situation of detection and punishment. Apart from the fact that corrupt transactions are difficult to observe anyway, entirely riskless corrupt transactions do not even exist in real life. This provides another justification for approaching the problem of corruption in a controlled experiment.

\section{Design}

Parties who are necessarily involved in corruption are the principal, the agent and the briber. Any experimenter who attempted to put subjects into the position of the briber would have a severe difficulty to overcome: The briber's behavior either reflects his 
attitude towards corruption, or his expectation about the agent's reaction on being offered a bribe, or both. We achieve a clearer interpretation by simply simulating the bribers' offers ourselves, and letting the subjects take the part of the agent.

In the first (non-risk) treatment, subjects were mostly students, who attended the showing of the film The Usual Suspects organized by the students' film club, a self-financed non-profit organization which volunteered as the "principal" in this experiment. Before the film started, they were requested to presume the following situation: A 200 German Mark-banknote (about 102 Euro) which belongs to the film club has fallen into a drain-pipe and cannot be retrieved without the help of a plumber firm. The film club has asked the subject to select on behalf of the film club the most favorable plumber firm out of a range of ten offers. According to the instructions which were distributed to the subjects, each of the ten firms made a bid composed of two parts: The price which the film group would have to pay, and an amount of money the decision maker would receive from the plumber for obtaining the contract (see Table 2). In this first treatment the film club is entirely passive in that it cannot observe the offers made by the plumber firms. Subjects were asked to fill out the form stating their decision, their field and semester of study, and sex as well as their name or pseudonym. They were assured that after the film one of the sheets would be randomly drawn, and that the payments would confidentially be made to the lucky-decision maker and to the film group, which would receive 200 Marks minus the payment to the successful plumber $^{12}$.

\section{Table 2 about here}

In order to test the hypothesis that payment matters, on about half of the instructions the following sentence was added (printed bold):

\footnotetext{
${ }^{12}$ See Bolle (1990) on the reliability of experiments with probabilistic rewards.
} 
"If your sheet is drawn, you will receive an extra payment of 40 German Marks, no matter which firm you choose."

In the second treatment we introduced the possibility of corruption being detected. Everything else remained the same as in the first treatment. Subjects were again mostly students who attended the film club's showing of Train Spotting. They were told (orally and in the written instructions) that, after the sheet was drawn, a random mechanism would determine whether corrupt agents would go undetected - in which case payments would be made as in the first treatment - or get detected, in which case the cheapest firm would get the contract and the film group paid accordingly, whereas the agent would receive nothing. Throwing a dice determined the detection as shown in Table 3 (taken from the instructions).

Table 3 about here

Again, about half of the subjects would receive a fixed payment of 40 German Marks if their sheets was drawn, which they would now lose in the case of detected corruption.

190 individuals participated in the first treatment, of which 30 had to be excluded because of their failure to report their field of study, semester, or sex. Of the remaining 160 subjects 78 were female, 104 non-economists, ${ }^{13}$ and 81 were rewarded a fixed payment of $40 \mathrm{DM}$ in case their sheet was drawn. First year students constituted $31 \%$ of total population, the respective figures for second, third, forth, fifth year students and those above were $16 \%, 17 \%, 17 \%, 13 \%$, and $7 \%$.

The second treatment was carried out on 255 subjects of which 25 had to be dropped due to incomplete response forms. Of the remaining 230 individuals, 99 were female, 145 non-economist, and 112 were to receive a fixed payment of $40 \mathrm{DM}$ if selected.

13 The economists consist of student enrolled in economics, agricultural economics, and economic pedagogy. Our results (not reported) indicate that the latter two groups behaved similar to 'pure' economists as compared to non-economists; therefore we aggregated them as one group. 
Students were distributed over their years of study ( $1^{\text {st }}, 2^{\text {nd }}, 3^{\text {rd }}, 4^{\text {th }}, 5^{\text {th }}$ and above) with: $34 \%, 20 \%, 13 \%, 17 \%, 9 \%$, and 7\%, respectively. All results (including descriptive figures and tables) refer only to the subjects who fully completed their response form.

\section{Results}

Figure 1 gives a first impression of the remarkably different distributions of bribes in the non risk treatment (shown in light gray) and the risk treatment (dark shaded). Surprisingly, the mean bribe is somewhat higher in the risk treatment: 91.4 DM versus 87.9 DM. Yet, the different distribution at both tails of the distribution is even more noteworthy.

Figure 1 about here

Of the population $9.4 \%$ were honest in the non risk treatment compared to only $0.9 \%$ in the risk treatment! For the first three categories (bribes between 0 and 32) the share was $19.4 \%$ in the non-risk treatment and $4.8 \%$ in the risk treatment. Monitoring and thus possible detection obviously reduces honesty. This finding is in accordance with the notion of intrinsic motivation being crowded out by monetary rewards or auditing by the principal. This is an amazing result which clearly contradicts any simple recipe for lower corruption through stricter law enforcement.

However, deterrence is at work at the same time. On the right tail of the distribution we see that risk of detection reduces the percentage of people who choose the maximum bribe: It falls from $28.8 \%$ to $12.6 \%$. The pattern becomes even clearer when we take the detection probability into account. Table 4 shows the detection probabilities and the expected bribes. Very high levels of corruption (A9, A10) become less rewarding than lower levels due to the rising risk of detection and thus people are deterred from choosing these options compared to the non-risk treatment. Note that from a purely self- 
interested perspective A5, A7, and A9 are irrational choices because the expected bribe can be increased without increasing risk. We should expect self-interest to be the dominating motive at the right tail of the distribution, i.e. at high levels of corruption. Indeed, the irrational choices have a very low density compared to their more rewarding alternatives of equal risk (A6, A8, A10), indicating that individuals on this side of the distribution react to law enforcement in a systematic, rational way as predicted by the economic theory of crime and punishment. This finding is supported by the observation that the most frequently chosen corruption levels are those with the highest expected return - 39 percent opted for an expected return of 53.3 DM (A6) and 25 percent for 56 DM (A8), which entails a higher detection probability than A6. This total of 64 percent for the two most profitable options in the risky case compares to only 34 percent in the non-risky case. What this means is that although deterrence is at work reducing the very high-level corruption (A9 and A10), people become more inclined to follow their pure self-interest also on the high end of corruption. Thus, monitoring destroys intrinsic motivation to keep corruptibility within some bounds not only at the lower end of the distribution, but also on the higher end. The net effect of reduced intrinsic motivation for honesty (or lower levels of corruption) on the one hand and increased deterrence on the other hand is therefore a priori undetermined. In our case, the introduction of monitoring has increased corruption.

In order to better understand the forces at work and to test the hypotheses put forward in sect. 2, we ran ordered logit regressions for both treatments. Results are reported in Table 5 and 6.

Tables 5 and 6 about here

It turns out that a fixed sum which is paid by the principal independent of the bribe does not significantly change the corruptibility of the agents in the non-risk case. Thus, we could not find any evidence for a loyalty effect. In contrast, in the risk treatment those 
who received a fix payment were significantly less inclined to accept bribes or inclined for lower bribes (at the 11 percent significance level). ${ }^{14}$ This indicates that higher opportunity costs in terms of a foregone fix payment in case of detection reduces the level of corruption. Our finding is again in accordance with the traditional view of crime and punishment because the existence of a fix payment effectively increases the penalty if caught of being bribed.

An interesting gender pattern emerges in the two treatments. While overall women behave no differently than men in the no risk situation, they exhibit a significantly lower willingness to accept bribes in the risky situation. This supports the notion that women are more risk averse than men.

Students of economics are more corrupt than their non-economic counterparts, but this difference vanishes completely in the presence of possible detection. This implies that economists behave with more self-interest to begin with, but in real life situations where risks are present they behave no differently. A cynic interpretation would be that the intrinsic motivation for cooperation and fairness that is destroyed through monitoring did not exist to the same extent for economists at the outset. Lastly, we included the number of semesters because Robert Frank et al. found cooperation to increase as students progress in their studies. We could not find such effect in either treatment.

We note one inherent technical problem with our analysis. In the risky situation there are four choices $(\mathrm{A} 3,5,7,9)$ which are irrational from a purely self-interested point of view, as the expected return can be increased at constant risk by switching to the next alternative. Any ordered logit analysis, however, assumes that the same forces govern

\footnotetext{
${ }^{14}$ We must be careful in interpreting the coefficients of this ordered logit model. The probability of a bribe to fall in category $i$ is $\operatorname{Prob}($ Bribe $=i)=\Lambda\left(\mu_{i}-\boldsymbol{\beta}^{\prime} \mathbf{x}\right)-\Lambda\left(\mu_{i-1}-\boldsymbol{\beta}\right.$ 'x $)$, where $\Lambda$ is the logistic cdf., $\boldsymbol{\beta}$ and $\mathbf{x}$ the vectors of coefficients and of exogenous variables, and the $\mu$ 's are the estimated cutoff points for each class $\left(\mu_{i}>\mu_{i-1}\right)$. Thus, for positive $\beta$ s an increase of the respective $\mathrm{x}$ shifts probability mass in higher order cells; the greater $\beta$, the stronger this shift. The net effect for each class is given by $\partial \operatorname{Prob}(\operatorname{Bribe}=i) / \partial \mathbf{x}=$ $\left(\lambda\left(\mu_{i-1}-\beta^{\prime} \mathbf{x}\right)-\lambda\left(\mu_{i}-\beta^{\prime} \mathbf{x}\right)\right) \boldsymbol{\beta}$ which can have either sign for the inner classes. Therefore, strictly speaking the existence of a fixed pay shifts probability mass in lower categories of bribes.
} 
the switch from one category to the next, regardless of the category (cf. fn. 14). However, switching from A6 to A7, i.e. from a rational choice to an irrational one, will presumably be governed by a different rationale than switching from A7 to A8. A purely self-interested individual would decide between rational choices, say A6 and A8. To address this problem we have recoded the dependent variable BRIBEADJ and treated the irrational choice and its rational alternative with the same detection probability as one category (e.g., A5 and A6, A7 and A8, etc.). Results were only mildly affected by this transformation. ${ }^{15}$

In order to establish the different behavior in the two treatments more formally, we ran a joint regression for the combined sample and allowed for interaction effects of the exogenous variables with a dummy RISK which is one for the risk treatment and zero otherwise. Wherever they turn out significant, a difference in behavior is formally established. ${ }^{16}$ Results are reported in Table 7.

Table 7 about here

The estimates support our previous findings: ${ }^{17}$ The influence of gender is insignificant, but the interaction effect is significantly negative underlining the greater risk aversion of women. Economists are more corrupt in the non-risk treatment leading to a significantly positive estimate for ECON. The interaction effect however is significantly negative of almost equal absolute magnitude, thereby nullifying the impact of economics in the risk treatment. Only for FIXPAY the differential effect is insignificant. Note that both the direct and the interaction effect have the same sign: Although the direct effect and the interaction effect are both insignificant, the fixed pay effect in the risk treatment, which

\footnotetext{
${ }^{15}$ Results are available upon request.

${ }^{16}$ Note that we still impose the restriction of equal cutoff points for both subsamples, which might not be justified.

17 Since SEMESTER did not show any significant effect in either sample, we dropped it from the regression. Again, we ran the same regression with the alternatively recoded (0-5) endogenous variable BRIBEADJ. The results were not markedly affected by this.
} 
is the sum of both effects, turns out significant at the eleven percent level. It seems fair to conclude that the overall behavior in both treatments follows systematically different rationales.

\section{Conclusions}

In this paper we have reported on the first experiment on determinants of corruption. As a further novelty of our approach, we have conducted the same experiment on corruption in a situation where people faced the risk of being caught and one in which they did not. This allows us to analyze the deterrent effect of monitoring on corruption as well as its effect on the intrinsic motivation for honesty or low levels of corruption. It turns out that both forces are at work - a detection probability that is increasing with the level of corruption makes high-end corruption less rewarding. People react systematically to it by reducing high-level corruption. At the same time, however, surveillance destroys the intrinsic motivation for honesty or low levels of corruption. People become dramatically less inclined to be honest when monitored! Probability mass is shifted from both tails of the distribution to those medium and high levels of corruption that exhibit the highest expected returns. The net effect on overall corruption is thus a priori undetermined. In our case, surveillance increases overall corruptibility.

The comparison of risk and non-risk treatment provides further interesting insights into the determinants of corruption. It is shown that women behave no differently than men in the non-risk treatment, but that they are significantly less corruptible in risky (real world) situations indicating a higher degree of risk aversion. We include a fixed payment for about half of the subjects, which does not reduce corruptibility in the nonrisk situation, but does so in the risky situation. In other words, we do not find any fairness or loyalty consideration at work which would have implied that those who feel 
treated well by the principal would have been less corruptible also in the non-risk treatment. There is however evidence for a deterrent opportunity cost effect - people with a fix payment which is lost in case of detection are less inclined to corruption. Lastly, students of economics show higher levels of corruption in the non-risk treatment indicating that they behave more self-interested to begin with, but this difference disappeared in the presence of possible detection.

Our findings have important policy implications, even though experiments on corruption are necessarily somewhat artificial because real life experiments on corruption would be unethical. If surveillance crowds out intrinsic motivation in an experiment like ours it will certainly crowd out this motivation in real world situations. This implies that the true costs of monitoring are higher than the pecuniary costs of the monitoring personnel and equipment and that especially for low frequency surveillance the costs in terms of crowded-out motivation for honesty may well exceed the gains from higher deterrence. Our results suggest that depending on the degree of prevailing corruption it is optimal to either monitor with a high frequency or not to monitor at all.

Acknowledgments: We are indebted to Johann Graf Lambsdorff for calling our attention to Fujimori's gender policy and to Alireza Jay Naghavi for valuable comments.

\section{References}

Becker, G.S., 1968. Crime and Punishment: An Economic Approach. Journal of Political Economy 76, 169-217.

Becker, G.S., Stigler, G.J., 1974. Law Enforcement, Malfeasance, and Compensation of Law Enforcers. Journal of Legal Studies 3, 1-18.

Besley, T., McLaren, J., 1993. Taxes and Bribery: The Role of Wage Incentives. Economic Journal 103, 119-141. 
Bolle, F., 1990. High Reward Experiments Without High Expenditure for the Experimenter? Journal of Economic Psychology 11, 157-167.

Bolton, G.E., Katok, E., 1995. An experimental test for gender differences in beneficent behavior. Economics Letters 48, 287-292.

Brinig, M.E., 1997. Why Can't a Woman Be More Like a Man? Or Do Gender Differences Affect Choice?, Paper presented at the Annual Meeting of the American Law and Economics Association.

Charness, G., 1997. Attribution and Reciprocity in a Simulated Labor Market: An Experimental Investigation, mimeo.

Donkers, B., Melenberg, B, van Soest, A., 1998. Estimating risk attitudes using lotteries; a large sample approach, mimeo, Tilburg University.

Eckel, C.C., Grossman, P.J., 1998. Are Women Less Selfish Than Men? Evidence from Dictator Experiments. Economic Journal 108, 726-735.

Falk, A., Gächter, S., Kovács, J., forthcoming. Intrinsic Motivation and Extrinsic Incentives in a Repeated Game with Incomplete Contracts. Journal of Economic Psychology.

Fehr, E., Kirchsteiger, G., Riedl, A., 1993. Does fairness prevent market clearing? An experimental investigation. Quarterly Journal of Economics 108, 437-460.

Fehr, E., Gächter, S., 1998. Reciprocity and economics: The economic implications of Homo Reciprocans. European Economic Review 42, 845-859.

Frank, B., Schulze, G., forthcoming. How Tempting is Corruption? - More Bad News About Economists. Journal of Economic Behavior and Organization.

Frank, R.H., Gilovich, T., Regan, D.T., 1993. Does Studying Economics Inhibit Cooperation? Journal of Economic Perspectives 7(2), 159-171.

Frey, B.S., 1993. Shirking or work morale? The impact of regulating. European Economic Review 37, 1523-1532.

Frey, B.S. 1997. Not Just For the Money. Elgar, Aldershot.

Frey, B.S., Oberholzer-Gee, F., 1997. The Cost of Price Incentives: An Empirical Analysis of Motivation Crowding-Out. American Economic Review 87, 746-755.

Gneezy, U., Rustichini, A., 1998. Pay Enough - Or Don't Pay At All, mimeo.

Goel, R.K., Rich, D.P., 1989. On the economic incentives for taking bribes. Public 
Choice 61, 269-275.

Jianakoplos, N.A., Bernasek, A., 1997. Are Women More Risk Averse?, mimeo, Colorado State University.

Kaufmann, D., 1997. Corruption: The Facts. Foreign Policy No.107, 114-131.

Klitgaard, R., 1996. National and International Strategies for Reducing Corruption. In: OECD Symposium on Corruption and Good Governance, Paris: OECD working papers No.78, 37-54.

Levitt, S.D., 1997. Using Electoral Cycles in Police Hiring to Estimate the Effect of Police on Crime. American Economic Review 87, 270-290.

Moody-Stuart, G., 1997. Grand Corruption. World View Publishing, Oxford.

Shapiro, C., Stiglitz, J.E., 1984. Equilibrium Unemployment as a Worker Discipline Device. American Economic Review 74, 433-444.

Spinellis, D., 1996. The Phenomenon of Corruption and the Challenge of Good Government. In: OECD Symposium on Corruption and Good Governance, Paris: OECD working papers No.78, 19-34.

Tanzi, V., 1998. Corruption around the World: Causes, Consequences, Scope, and Cures. IMF Staff Papers 45, 559-594.

Tirole, J., 1996. A Theory of Collective Reputations (with applications to the persistence of corruption and to firm quality). Review of Economic Studies 63, $1-22$.

Van Rijkeghem, C., Weder, B., 1997. Corruption and the Rate of Temptation: Do Low Wages in the Civil Service Cause Corruption? IMF working paper WP/97/73, Washington. 
Figure 1: Distribution of bribes for non-risk and risk treatments

$\square$ Non-risk treatment $\square$ Kisk treatment 
Table 1: Motivation which drives behavior in different treatments according to hypotheses

\begin{tabular}{|c|c|c|c|}
\hline Group of hypotheses & Real life (with risk) & Riskless situation & Differential effect \\
\hline \multirow{5}{*}{$\begin{array}{l}2.1 . \\
\text { (Auditing) }\end{array}$} & Deterrence of & Intrinsic & Mainly deterrence for \\
\hline & corruption, & motivation for & some of the subjects; \\
\hline & Lesser intrinsic moti- & being honest & crowding out of \\
\hline & vation for being honest & & intrinsic motivation for \\
\hline & & & others \\
\hline \multirow{2}{*}{$\begin{array}{l}2.2 . \\
\text { (Pay) }\end{array}$} & Higher opportunity costs & Reciprocity & Higher opportunity \\
\hline & Reciprocity & & costs \\
\hline \multirow{4}{*}{$\begin{array}{l}2.3 . \\
\text { (Gender) }\end{array}$} & Higher general & Women's higher & Higher risk aversion \\
\hline & cooperativeness of & general & \\
\hline & women, & cooperativeness & \\
\hline & Higher risk aversion & & \\
\hline
\end{tabular}


Table 2: The firms' bids of price and bribe (no-risk treatment)

$\begin{array}{lll} & \text { price which the film group } & \text { amount which you } \\ \text { firm } & \text { has to pay (German Marks) } & \text { receive (German Marks) }\end{array}$

A1

A2

A3

A4

A5

A6

A7

A8

A9

A10
20

40

60

80

100

120

140

160

180

200
0

16

32

48

64

80

96

112

128

144 
Table 3: The firms' bids of price and bribe, and probability of detection

\begin{tabular}{|c|c|c|c|c|}
\hline \multirow[t]{4}{*}{ firm } & price which the & amount which & probability that & You will be \\
\hline & film group has & you receive & you are detected & detected when \\
\hline & to pay (German & (German & & the dice falls as \\
\hline & Marks) & Marks) & & follows: \\
\hline A1 & 20 & 0 & 0 & - \\
\hline $\mathrm{A} 2$ & 40 & 16 & 0 & - \\
\hline A3 & 60 & 32 & $17 \%$ & 6 \\
\hline A4 & 80 & 48 & $17 \%$ & 6 \\
\hline A5 & 100 & 64 & $33 \%$ & 5 or 6 \\
\hline A6 & 120 & 80 & $33 \%$ & 5 or 6 \\
\hline A7 & 140 & 96 & $50 \%$ & 4,5 or 6 \\
\hline A8 & 160 & 112 & $50 \%$ & 4,5 or 6 \\
\hline A9 & 180 & 128 & $67 \%$ & $3,4,5$ or 6 \\
\hline A10 & 200 & 144 & $67 \%$ & $3,4,5$ or 6 \\
\hline
\end{tabular}


Table 4: Expected bribe in the risk treatment

\begin{tabular}{|l|c|c|c|c|c|c|c|c|c|c|}
\hline Firm & A1 & A2 & A3 & A4 & A5 & A6 & A7 & A8 & A9 & A10 \\
\hline Bribe & 0 & 16 & 32 & 48 & 64 & 80 & 96 & 112 & 128 & 144 \\
\hline $\begin{array}{l}\text { Probability of } \\
\text { detection }\end{array}$ & \multicolumn{2}{|c|}{0} & \multicolumn{2}{|c|}{$1 / 6$} & \multicolumn{2}{|c|}{$1 / 3$} & \multicolumn{2}{|c|}{$1 / 2$} & \multicolumn{2}{|c|}{$2 / 3$} \\
\hline Expected bribe & 0 & 16 & 26.7 & 40 & 42.7 & 53.3 & 48 & 56 & 42.7 & 48 \\
\hline
\end{tabular}


Table 5: Ordered Logit Estimates for the Non-risk treatment

Endogenous variable: recoded variable BRIBE| (0-9)

\begin{tabular}{|c|c|c|c|c|c|c|}
\hline Variables & Coefficient & Std. Err. & $\mathrm{Z}$ & $\mathrm{P}>|\mathrm{z}|$ & \multicolumn{2}{|c|}{ [95\% Conf. Interval] } \\
\hline FEMALE & .2098802 & .3083278 & 0.681 & 0.496 & -.3944311 & .8141916 \\
\hline SEMESTER & -.0313866 & .0405321 & -0.774 & 0.439 & -.1108281 & .0480548 \\
\hline ECON & 1.489207 & .4439873 & 3.354 & 0.001 & .6190084 & 2.359407 \\
\hline FIXPAY & -.0609903 & .2827602 & -0.216 & 0.829 & -.6151902 & .4932096 \\
\hline \multicolumn{2}{|c|}{ Ancillary parameters: } & & & & & \\
\hline _cut1 | & -2.11552 & .4415121 & & & & \\
\hline _cut2 & -1.625851 & .4151927 & & & & \\
\hline _cut3 & -1.263652 & .4043552 & & & & \\
\hline _cut4 & -.9318863 & .3991225 & & & & \\
\hline _cut5 & -.3278272 & .395498 & & & & \\
\hline _cut6 & .2341984 & .3938713 & & & & \\
\hline _cut7 & .5323517 & .3941862 & & & & \\
\hline _cut8 & .910475 & .3986124 & & & & \\
\hline _cut9 & 1.19874 & .4048921 & & & & \\
\hline
\end{tabular}

Number of obs $=160$

chi2 $(4)=12.70 \quad$ Prob $>$ chi $2=0.0129$

Log Likelihood $=-332.54979 \quad$ Pseudo R2 $=0.0187$

cutoff points are reported for referees' information only, we suggest to leave them out in a final version. 
Table 6: Ordered Logit Estimates for the Risk Treatment

Endogenous variable: recoded variable BRIBE (0-9)

\begin{tabular}{|c|c|c|c|c|c|c|}
\hline Variable & Coefficient & Std. Err. & $\mathrm{Z}$ & $\mathrm{P}>|\mathrm{z}|$ & \multicolumn{2}{|c|}{ [95\% Conf. Interval] } \\
\hline FEMALE & -.7307489 & .2600093 & -2.810 & 0.005 & -1.240358 & -.22114 \\
\hline SEMESTER & .0135253 & .0336113 & 0.402 & 0.687 & -.0523516 & .0794022 \\
\hline ECON & -.0341022 & .2991481 & -0.114 & 0.909 & -.6204217 & .5522174 \\
\hline FIXPAY & -.3811728 & .2397 & -1.590 & 0.112 & -.8509762 & .0886306 \\
\hline \multicolumn{3}{|c|}{ Ancillary parameters } & & & & \\
\hline _cut1 & -5.261227 & .7585062 & & & & \\
\hline _cut2 & -3.718512 & .4307861 & & & & \\
\hline _cut3 & -3.506667 & .4062838 & & & & \\
\hline _cut4 & -2.483722 & .3299964 & & & & \\
\hline _cut5 & -2.061035 & .3124774 & & & & \\
\hline _cut6 & -.1824743 & .2781623 & & & & \\
\hline _cut7 & -.0139046 & .2778877 & & & & \\
\hline _cut8 & 1.360301 & .2972339 & & & & \\
\hline _cut9 & 1.547563 & .3047926 & & & & \\
\hline
\end{tabular}

Number of obs $=230$

$\operatorname{chi} 2(4)=10.92$

Log Likelihood $=-390.01251$
Prob $>$ chi $2=0.0275$

Pseudo R2 $=0.0138$ 
Table 7: Ordered Logit Estimates for the Combined Sample

Dependent variable BRIBE (recoded 0-9)

\begin{tabular}{|c|c|c|c|c|c|c|}
\hline & Coefficient & Std. Err. & $\mathrm{Z}$ & $\mathrm{P}>|\mathrm{z}|$ & \multicolumn{2}{|c|}{ [95\% Conf. Interval] } \\
\hline FEMALE & .281639 & .3427632 & 0.822 & 0.411 & -.3901646 & .9534426 \\
\hline ECON & 2.067453 & .4789252 & 4.317 & 0.000 & 1.128776 & 3.006129 \\
\hline FIXPAY & -.0580094 & .3084437 & -0.188 & 0.851 & -.6625479 & .5465292 \\
\hline RISK & .9883995 & .4031554 & 2.452 & 0.014 & .1982294 & 1.77857 \\
\hline RISK*FIXPAY & -.2545894 & .3795302 & -0.671 & 0.502 & -.9984549 & .4892761 \\
\hline RISK*FEMALE & -.7979296 & .4171629 & -1.913 & 0.056 & -1.615554 & .0196948 \\
\hline RISK*ECON & -2.057306 & .5520541 & -3.727 & 0.000 & -3.139312 & -.9753004 \\
\hline _cut1 & -2.574875 & .3953666 & \multicolumn{3}{|c|}{ (Ancillary parameters) } & \\
\hline _cut2 | & -1.89421 & .3620292 & & & & \\
\hline _cut3 & -1.588871 & .3532198 & & & & \\
\hline _cut4 & -1.018847 & .3434406 & & & & \\
\hline _cut5 | & -.5151379 & .3408239 & & & & \\
\hline _cut6 & .7621036 & .3428316 & & & & \\
\hline _cut7 | & .9824959 & .3438098 & & & & \\
\hline _cut8 | & 1.888287 & .3515923 & & & & \\
\hline _cut9 & 2.121942 & .3548017 & & & & \\
\hline
\end{tabular}

Ordered Logit Estimates $\quad$ Number of obs $=390$

$\operatorname{chi} 2(7)=27.48 \quad$ Prob $>\operatorname{chi} 2=0.0003$

Log Likelihood $=-764.80698 \quad$ Pseudo R2 $=0.0176$ 
For referees' information only

Estimates for the recoded system, dependent variable BRIBEADJ, as explained on page 16, risk treatment only.

Dependent variable BRIBEADJ (0-5)

\begin{tabular}{|l|l|l|l|l|l|l|}
\hline & Coef. & Std. Err. & $\mathrm{z}$ & $\mathrm{P}>|\mathrm{z}|$ & \multicolumn{2}{|c|}{$[95 \%$ Conf. Interval] } \\
\hline female | & -.6701495 & .2634834 & -2.543 & 0.011 & -1.186567 & -.1537316 \\
\hline semester | & .0237657 & .0342468 & 0.694 & 0.488 & -.0433567 & .0908881 \\
\hline econ | & -.058787 & .3049663 & -0.193 & 0.847 & -.6565099 & .5389359 \\
\hline fixpay | & -.3695991 & .2449503 & -1.509 & 0.131 & -.8496929 & .1104947 \\
\hline
\end{tabular}

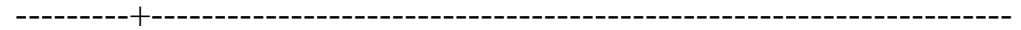

_cut1 | $-5.181127 .7588835 \quad$ (Ancillary parameters)

_cut2| - $3.638195 \quad$ 4313595

_cut3 | $-2.404018 \quad 3311727$

_cut4 | - - 1079705 .2814592

_cut5 | $1.42314 \quad 3028721$

Ordered Logit Estimates

Number of obs $=230$

$\operatorname{chi} 2(4) \quad=9.27$

Log Likelihood $=-307.01184$

Prob $>$ chi $2=0.0548$

$$
\text { Pseudo R2 }=0.0149
$$

